\title{
Clinical management of patients with Cushing syndrome treated with mifepristone: consensus recommendations
}

David R. Brown ${ }^{1}$, Honey E. East ${ }^{2}$, Bradley S. Eilerman ${ }^{3}$, Murray B. Gordon ${ }^{4}$, Elizabeth E. King ${ }^{5}$, Laura A. Knecht ${ }^{6}$, Brandon Salke', Susan L. Samson ${ }^{8}$, Kevin C. J. Yuen ${ }^{9}$ and Hanford Yau ${ }^{10^{*}}$

\begin{abstract}
Background: While surgery is the first-line treatment for patients with endogenous hypercortisolism (Cushing syndrome [CS]), mifepristone has been shown to be a beneficial medical treatment option, as demonstrated in the SEISMIC (Study of the Efficacy and Safety of Mifepristone in the Treatment of Endogenous Cushing Syndrome) trial. Mifepristone is a competitive glucocorticoid receptor antagonist and progesterone receptor antagonist that is associated with several treatment effects and adverse events that clinicians need to be aware of when considering its use. The objective of this review was to provide updated clinical management recommendations for patients with CS treated with mifepristone.
\end{abstract}

Methods: A panel of endocrinologists from the US with extensive experience in treating patients with CS, including with mifepristone, convened as part of a clinical advisory board to develop a consensus on the practical, real-world clinical management of patients on mifepristone.

Results: Comprehensive considerations and recommendations are provided for managing mifepristone-associated effects, including symptoms of cortisol withdrawal, hypokalemia, and change in thyroid function; effects related to its antiprogesterone activity; and rash. Additional management strategies to address concomitant medications and special clinical situations, such as surgery and use in specific populations, are also provided.

Conclusion: Safe and effective use of mifepristone requires clinical judgment and close patient monitoring to ensure optimal clinical outcomes. These consensus recommendations provide useful, practical guidance to clinicians using mifepristone.

Keywords: Cushing syndrome, Drug effects, Education

\section{Introduction}

Surgical resection of the underlying tumor is first-line therapy for patients with endogenous hypercortisolism caused by Cushing syndrome (CS), regardless of its etiology [1]. Medical treatment options, including

\footnotetext{
* Correspondence: hanfordyau@gmail.com

${ }^{10}$ Division of Endocrinology, Diabetes, and Metabolism, The University of Central Florida College of Medicine, 13800 Veterans Way, Orlando, FL 32827, USA

Full list of author information is available at the end of the article
}

pituitary-directed agents, steroid synthesis inhibitors, and glucocorticoid receptor (GR) antagonists, may be used to treat persistent or recurrent disease if surgery fails, or if surgery is not feasible [1,2]. Medical therapy may also be used as an adjunctive bridge therapy to pituitary radiation while awaiting the effects of radiation [3], and as a preoperative treatment to address the effects of severe hypercortisolism and associated complications [4].

(c) The Author(s). 2020 Open Access This article is licensed under a Creative Commons Attribution 4.0 International License, which permits use, sharing, adaptation, distribution and reproduction in any medium or format, as long as you give appropriate credit to the original author(s) and the source, provide a link to the Creative Commons licence, and indicate if changes were made. The images or other third party material in this article are included in the article's Creative Commons licence, unless indicated otherwise in a credit line to the material. If material is not included in the article's Creative Commons licence and your intended use is not permitted by statutory regulation or exceeds the permitted use, you will need to obtain permission directly from the copyright holder. To view a copy of this licence, visit http://creativecommons.org/licenses/by/4.0/ The Creative Commons Public Domain Dedication waiver (http://creativecommons.org/publicdomain/zero/1.0/) applies to the data made available in this article, unless otherwise stated in a credit line to the data. 
Mifepristone is a competitive GR and progesterone receptor (PR) antagonist approved by the US Food and Drug Administration (FDA) in 2012 to control hyperglycemia secondary to hypercortisolism in patients with endogenous hypercortisolism (Cushing syndrome) who have type 2 diabetes mellitus or glucose intolerance and have failed surgery or are not candidates for surgery. It is not for treatment of type 2 diabetes mellitus unrelated to endogenous CS.

The efficacy and safety of mifepristone in patients with CS was shown in the pivotal 6-month, multicenter, phase 3 SEISMIC (Study of the Efficacy and Safety of Mifepristone in the Treatment of Endogenous Cushing Syndrome) trial $(n=50)$ [5] and in several post-hoc analyses of SEISMIC [6-10]. In SEISMIC, clinically significant improvement was achieved in $87 \%$ of patients, as assessed by an independent review board. Because serum cortisol and adrenocorticotropic hormone (ACTH) levels remain unchanged or rise in response to GR antagonism associated with mifepristone, clinicians must monitor the patient's clinical and metabolic responses to assess efficacy (e.g., body composition, blood pressure, glucose, strength, clinical appearance, and psychiatric and cognitive function) [7]. Clinicians must also use clinical and metabolic responses to assess tolerability and safety. Mifepristone-induced effects include cortisol withdrawal symptoms (fatigue, nausea, vomiting, headache, arthralgia), antiprogesterone effects (endometrial thickening, vaginal bleeding), and changes in thyroid function [5]. Elevated cortisol levels that can occur due to mifepristone's mechanism of action [8] can saturate the binding capacity of $11 \beta$-hydroxysteroid dehydrogenase type 2 (11ßHSD2), leading to increased availability of cortisol to stimulate the mineralocorticoid receptor (MR) and resulting in edema, hypertension, and hypokalemia. Clinical improvement following mifepristone therapy may also necessitate adjustment of concomitant medications to prevent potential adverse effects. For example, before starting mifepristone, antidiabetes regimens should be evaluated and modified to reduce the risk of hypoglycemia. Previously published recommendations for the use of mifepristone were based primarily on the clinical experience derived from SEISMIC [1, 11, 12]. Updated clinical guidance is needed on the management of patients treated with mifepristone that reflects the clinical experience gained with this drug since FDA approval in 2012.

In May 2019, a panel of endocrinologists from the US with experience in treating patients with CS, including with mifepristone, convened as part of an advisory board to discuss experiences and reach a consensus on the real-world management of patients on mifepristone. This review summarizes their consensus opinions and is intended to provide clinically relevant suggestions, considerations, and strategies to help practicing clinicians appropriately manage and educate patients on mifepristone therapy, with a focus on safety and tolerability.

\section{Management of mifepristone's treatment effects and adverse effects}

Cortisol withdrawal symptoms

Patients with hypercortisolism may experience signs and symptoms of cortisol withdrawal (i.e., nausea, fatigue, headache) during mifepristone treatment. These signs and symptoms, however, and their severity, are wideranging and may vary depending on the duration and severity of the hypercortisolism. Of note, some of the signs and symptoms of cortisol withdrawal also resemble those of adrenal insufficiency (AI) [13, 14]. However, several objective signs of severe AI, including hypoglycemia, hyponatremia (primary AI), and hyperkalemia (primary AI) (Fig. 1) [8, 15-17] do not occur during mifepristone treatment [5, 8]. Paradoxically, hypokalemia and/or increases in blood pressure due to MR activation may occur indirectly with mifepristone treatment [5] because of elevated cortisol levels (see also Hypokalemia section, p. 3). These signs and symptoms have been more accurately described as excessive GR antagonism due to overtreatment. (Fig. 1) [8].

Of note, hypokalemia and hypertension can also occur as part of the disease state itself (see the Hypokalemia section below) and may not always indicate excess GR antagonism due to mifepristone. The signs and symptoms should also be considered in the context of the individual patient. In particular, any worsening, persistent, or difficult to treat hypokalemia and/or hypertension may indicate clinically significant excess GR antagonism. If excess GR antagonism is suspected, mifepristone should be temporarily discontinued and rescue therapy with dexamethasone considered $[8,11]$ at the discretion of the prescribing clinician. Dexamethasone is preferred over other glucocorticoids because of its longer half-life, lack of mineralocorticoid activity, and high affinity for GR [12]. See the Special clinical situations section (p. 9) for dexamethasone dosing recommendations.

Counseling patients on common cortisol withdrawal symptoms before starting mifepristone treatment may help with medication adherence. A brief office or telemedicine follow-up visit within 1-2 weeks may also help reassure patients experiencing cortisol withdrawal that the symptoms are expected, usually transient, and indicative of therapeutic efficacy. See Table 1 for guidance on managing common signs and symptoms of cortisol withdrawal, including headache, arthralgia, fatigue, nausea, and vomiting. Note that treatment with mifepristone can also unmask symptoms of underlying inflammatory and autoimmune disorders such as osteoarthritis, Hashimoto thyroiditis, rheumatoid arthritis, or lupus [18-20]. 




Fig. 1 Signs and symptoms associated with excess GR antagonism, cortisol withdrawal, and adrenal insufficiency $[8,15,16]$. ${ }^{\text {TT }}$ The presence of these signs and symptoms may not always be indicative of excess GR antagonism due to mifepristone and should also be considered in the context of the patient. ${ }^{b}$ Incidence and magnitude may depend on concomitant medications being taken with mifepristone. ${ }^{\circ}$ Occurs with primary adrenal insufficiency. Abbreviations: GR glucocorticoid receptor, MR mineralocorticoid receptor

Patients, caregivers, and other clinicians should be educated on recognizing the signs and symptoms suggestive of excess GR antagonism, such as hypertension and/or hypokalemia and encouraged to communicate their concerns to the physician managing mifepristone treatment for further assessment. Patients should be instructed to consult with the clinician managing mifepristone when other healthcare providers prescribe new medications, as these medications may interact with mifepristone. Encourage patients to carry a wallet card that contains information on mifepristone, the prescribing physician and pharmacy, the signs and symptoms suggestive of excess GR antagonism (especially hypokalemia), and the general importance of avoiding administration of systemic glucocorticoids for indications other than excess GR antagonism.

\section{Hypokalemia}

Hypokalemia is a frequent manifestation of CS [21, 22] due to excess cortisol saturating the oxidative capacity of $11 \beta \mathrm{HSD} 2$ to inactivate cortisol to cortisone. The excess available cortisol can then act on the MR, leading to MR activation [23]. GR antagonism with mifepristone may lead to further increases in cortisol, particularly in patients with $\mathrm{CD}$, which may potentially exacerbate hypokalemia. In SEISMIC, $44 \%$ of patients developed hypokalemia during mifepristone treatment [5]. Hypokalemia should be corrected prior to initiating treatment with mifepristone and potassium levels should be regularly monitored during treatment and dose escalation (Fig. 2) [16].

In addition to checking a baseline potassium level before starting mifepristone, renal function assessment (estimated glomerular filtration rate [eGFR]) and medication review are also advised to identify medications that may alter potassium levels and eGFR (e.g., angiotensin converting enzyme [ACE] inhibitors, angiotensin II receptor blockers [ARBs], loop diuretics, thiazides). For patients on loop or thiazide diuretics, depending on the indication (heart failure or hypertension), the clinician might consider dose adjustment or alternate therapies. Performing a dietary review with the patient and providing recommendations for a low-sodium diet, such as Dietary Approaches to Stop Hypertension (DASH), may also be beneficial [24].

To help further mitigate the risk of developing hypokalemia, a pre-treatment potassium level of at least $4.0 \mathrm{mEq} / \mathrm{L}$ is recommended. If pre-mifepristone potassium is $<4.0 \mathrm{mEq} / \mathrm{L}$, we recommend preemptive supplementary potassium prior to initiating mifepristone treatment. Furthermore, we recommend consideration of concomitant treatment with spironolactone. If spironolactone is not tolerated, then the alternative MR antagonist, eplerenone, may be used. See Fig. 2 for suggested spironolactone dosing recommendations. Additional dose modifications may be made based on clinical judgment. In SEISMIC, 28\% (14/50) of patients received spironolactone at doses up to $400 \mathrm{mg}$ daily [5].

\section{Endometrial thickening and vaginal bleeding}

Mifepristone is classified as a selective progesterone receptor modulator as well as a competitive GR antagonist. Because of PR modulation, mifepristone can cause endometrial thickening and vaginal bleeding $[25,26]$. Among women with available data from SEISMIC, $38 \%(10 / 26)$ experienced endometrial thickening, as 
Table 1 Summary of recommendations for the management of some common signs and symptoms of cortisol withdrawal



\section{Nausea and vomiting}

Mild nausea and vomiting (i.e., non-emergency setting)

-5-HT3 receptor antagonists are the first-line treatment. Do not exceed $8 \mathrm{mg}$ of oral ondansetron in order to minimize the potential for drug-drug interactions and side effects (e.g., fatigue)

-Alternative agents include promethazine or scopolamine patch

-Consult with pharmacy for potential drug-drug interactions

Intractable nausea/vomiting

-If patient is showing signs of volume depletion or is seeking emergency help, temporarily hold mifepristone and give dexamethasone

\section{Fatigue \\ Mild fatigue \\ - Reassure patients that this is a sign of therapeutic effect and may resolve over time \\ Moderate-severe fatigue \\ -For fatigue that interferes with the patient's activities of daily life, recommend additional laboratory assessments, such as thyroid function tests, complete blood count, iron panel, 25-hydroxy vitamin D level, and B12 level \\ -Address other comorbidities (e.g., obstructive sleep apnea) \\ Note: For intolerable symptoms of cortisol withdrawal, we recommend temporary holding of mifepristone and rechallenge later, restarting at a lower dose \\ Abbreviations: 5-HT3 5-hyroxytryptamine 3, NSAIDs nonsteroidal anti- inflammatory drugs, TENS transcutaneous electrical nerve stimulation}

detected by transvaginal ultrasound $[5,16]$. Although reported primarily among premenopausal women [5], cases of vaginal bleeding with mifepristone have also been reported among postmenopausal women [27]. Therefore, all non-hysterectomized women should be counseled on the risk of potential vaginal bleeding.

Providers should involve gynecology in the management and monitoring of endometrial effects of mifepristone, especially if a transvaginal ultrasound is performed [11]. The endometrial changes associated with PR modulators such as mifepristone are unique and are not indicative of hyperplasia, dysplasia, or malignancy [25, 26, 28]. We recommend that endometrial biopsies be read by pathologists familiar with the endometrial changes associated with PR modulators, to prevent potential misclassification [29, 30]. In the event of bleeding, systemic hormone treatment with progesterone will not be beneficial during mifepristone treatment. For some patients with endometrial thickening, a periodic planned mifepristone holiday, combined with a course of medroxyprogesterone to induce decidual bleeding, may be appropriate [31]. Afterwards, mifepristone may be restarted at the previous maintenance dose. Other options for vaginal bleeding management include dilation and curettage, endometrial ablation, and elective hysterectomy. Implications for future fertility should be discussed with premenopausal patients treated long-term with mifepristone. To our knowledge, there are no available studies on the use of a local intrauterine device to help prevent associated bleeding.

\section{Thyroid function}

Mifepristone use can alter thyroid function [5, 32]. In the SEISMIC trial, 19\% (8/42) of patients had reversible increases in thyroid-stimulating hormone (TSH) [5]. TSH increases accompanied by reductions in serum thyroxine (T4) have also been observed within 3 months of long-term mifepristone treatment (up to 40 months) [33]. The mechanisms behind the effects of mifepristone on thyroid function are not yet fully understood and likely differ in patients with primary hypothyroidism versus secondary (central) hypothyroidism. Effects may include increased TSH secretion secondary to hypothalamic and pituitary GR inhibition rather than, or in addition to, reduced thyroid hormone secretion [33]. Pre-existing autoimmune thyroid disease and hypothyroid symptoms may be masked by hypercortisolism [18] and unmasked by mifepristone treatment [18]. If possible, all patients should undergo baseline thyroid function testing before mifepristone is initiated. Regardless of whether a patient is on thyroid medication at baseline, we recommend monitoring TSH and free T4 during mifepristone titration, every 3 months during treatment, and if any signs or symptoms consistent with abnormal thyroid function develop. Monitoring total or free tri-iodothyronine (T3) levels in selected patients may also be of value. Additional monitoring and treatment recommendations are provided in Fig. 3 [34, 35]. Patients with central hypothyroidism may need substantial increases in their thyroid hormone requirement during mifepristone treatment [32]. In a small case series of patients with Cushing disease and central hypothyroidism, patients required a median levothyroxine dose increase 1.83 times the initial dose to achieve normal levels of free T4 [32]. Potential areas for future investigations include further elucidation of the effects of mifepristone on TSH secretion, T4 to T3 conversion, and thyroid-binding globulin levels. 


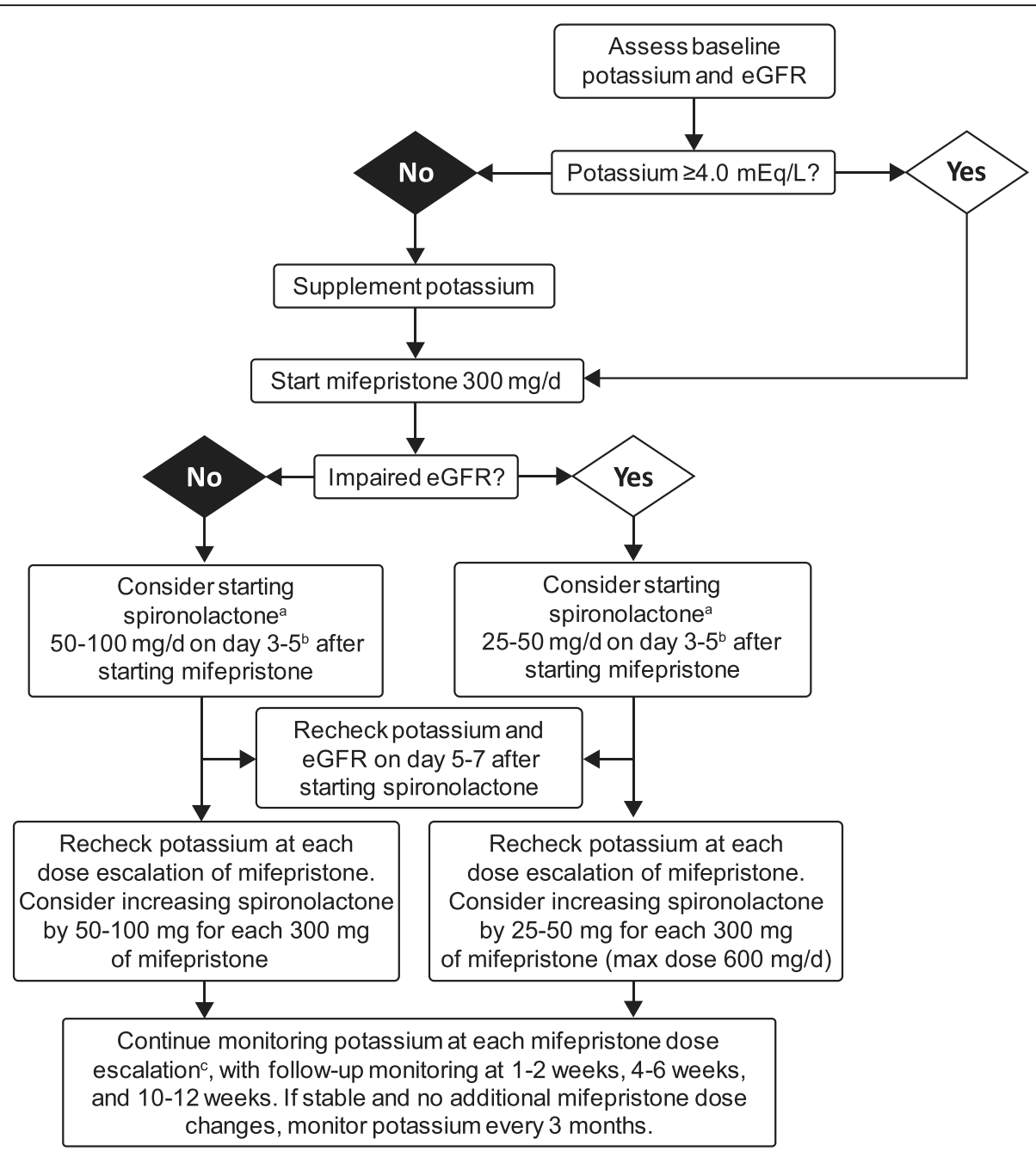

Fig. 2 Suggested potassium monitoring and spironolactone dosing algorithm for potassium. ${ }^{a}$ Note that all patients may not need proactive spironolactone. For instance, some patients, particularly those with adrenal disease may not experience substantial increases in cortisol (and associated MR activation) during mifepristone treatment. ${ }^{\mathrm{b}} \mathrm{MR}$ activation with mifepristone may take several days to occur. Direct patient to call clinician's office to report when the MR antagonist is started to facilitate appropriate follow-up. If spironolactone is not tolerated, consider an alternative MR antagonist, such as eplerenone. ' $C$ Check for signs of excess MR activation (e.g., edema, elevated blood pressure). Abbreviations: eGFR estimated glomerular filtration rate, MR mineralocorticoid receptor

\section{Rash}

There have been reports of rash following mifepristone treatment in patients with hypercortisolism, but published data are limited [16]. Mifepristone-associated rash is characterized as a maculopapular, pruritic rash that typically appears on an extremity and progresses to the trunk. The rash is generally self-limiting and does not reappear upon rechallenge [36].

Should a patient report a rash during treatment, the clinician should assess the patient and rule out anaphylaxis. Other types of rash related to hypercortisolemia, such as cutaneous fungal rash, or autoimmune-related rash (e.g., eczema) resulting from the reduction in cortisol activity should also be considered. Patients should be asked if any new medications have been started that may also be associated with rash. If concomitant treatment with a MR antagonist is planned, starting it 3-5 days after mifepristone is reasonable (see Fig. 2); this may facilitate identification of the causal agent if a rash should develop prior to initiation of the MR antagonist. Have the patient consult with a dermatologist if needed for management of pruritus. Examples of appropriate treatment options include diphenhydramine and hydroxyzine.

\section{Concomitant medication management}

Perform medication reconciliation periodically, especially following visits with outside providers who are not familiar with mifepristone's mechanism of action, side effects, and drug interactions. Mifepristone prolongs the QT interval in a dose-related manner [16]; 


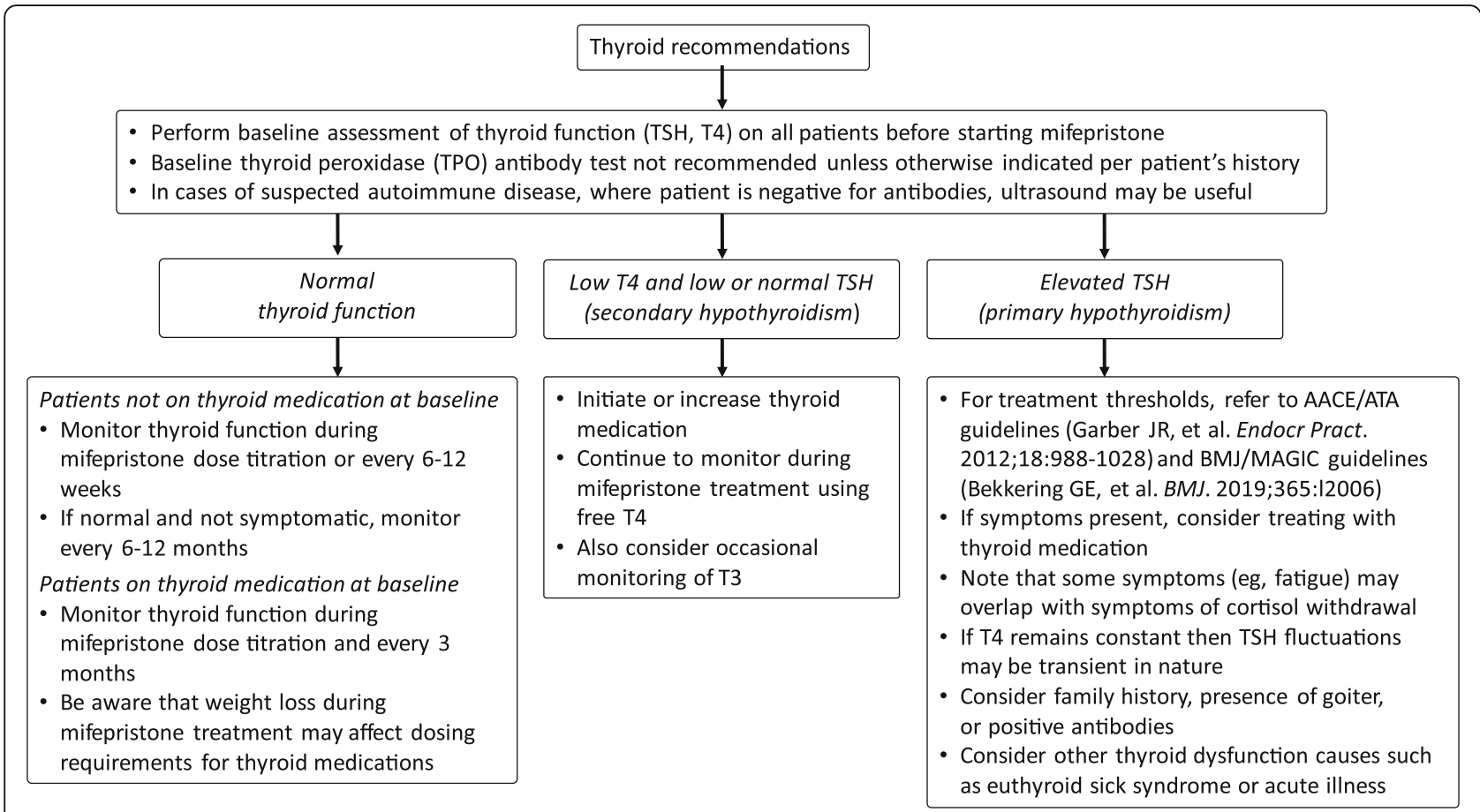

Fig. 3 Thyroid assessment recommendations during mifepristone treatment [34, 35]. Abbreviations: AACE American Association of Clinical Endocrinologists, ATA American Thyroid Association, BMJ British Medical Journal, MAGIC MAGIC (Making Grade the Irresistible Choice) Foundation, T3 tri-iodothyronine, T4 thyroxine, TSH thyroid-stimulating hormone

therefore, we strongly caution against using mifepristone with other medications that may prolong the QT interval. Advise patients to notify the mifepristone prescriber when any other provider makes a medication change. We also encourage proactive communication with other providers cautioning the use of any medications that affect potassium levels. Specific consensus recommendations to address the management of commonly encountered concomitant medications during mifepristone therapy, including antihypertensives, anticoagulants, and antihyperglycemic agents, are provided in Table 2 [37].

\section{Antihypertensives}

Mifepristone treatment may be associated with either a decrease in blood pressure due to inhibition of the effects of hypercortisolism or an increase in blood pressure due to cortisol-mediated MR activation [5]. Therefore, we do not consider it necessary to prophylactically reduce or discontinue antihypertensive medications before starting mifepristone provided patients are closely monitored. In general, when a patient is hypertensive at baseline, their blood pressure control should be optimized prior to starting mifepristone (spironolactone recommended as first-line option). An individualized approach to adjusting other antihypertensives may be needed, with particular attention to antihypertensives that can affect serum potassium levels (ARBs, ACE inhibitors, loop diuretics, thiazides). Monotherapeutic agents are preferred over combination formulations. Other antihypertensives (e.g., beta-blockers, alpha-blockers, calcium channel-blockers) may be indicated based on patient history.

Counsel patients to measure their blood pressure using a home blood pressure monitor during mifepristone treatment and report their results. Patients should be instructed to contact the office in the event of significant blood pressure changes or the development or worsening of peripheral edema. Consider discussing CS medication treatment with co-managing clinicians (e.g., PCP, cardiologist, nephrologist).

\section{Anticoagulants}

Mifepristone increases the concentration of warfarin. Refer to Table 2 for specific recommendations for monitoring and dosing warfarin when using mifepristone. The direct oral anticoagulant (DOAC) apixaban [37] may be used with mifepristone, but caution is required due to the potential for drug-drug interaction. Rivaroxaban [38] would not be a suitable DOAC because it is metabolized primarily by CYP3A (Table 3) [12]. All patients receiving anticoagulants should be counseled on the signs of bleeding and closely monitored. 
Table 2 Suggested recommendations for the management of concomitant antihypertensive, anticoagulant, and antidiabetes medications during mifepristone treatment

\begin{abstract}
Antihypertensives
-If patient is hypertensive at baseline, normalize blood pressure prior to starting mifepristone

-Recommend MR antagonist (spironolactone) as first-line antihypertensive agent after assessment of renal function (eGFR). Start spironolactone before mifepristone if the patient's baseline characteristics include hypertension, low or low-normal potassium levels, and/or edema.

- Use clinical discretion when adjusting other antihypertensive agents, with particular focus on antihypertensive agents (e.g., ACE inhibitors, ARBs, loop diuretics, thiazides) that can affect serum potassium levels and eGFR, particularly when up-titrating spironolactone

•Be mindful of combination antihypertensive medications. Single agents may be preferable.

-If the patient is receiving a calcium channel antagonist, note there may be drug-drug interactions between mifepristone and both diltiazem and verapamil. Dihydropyridines are associated with edema, which may be exacerbated by MR activation
\end{abstract}

\title{
Anticoagulants
}

Aspirin

-Low-dose aspirin $(81 \mathrm{mg})$ is acceptable with mifepristone. Do not use NSAIDs due to potential drug-drug interaction.

Thienopyridines

-Dose changes not recommended

Direct oral anticoagulants (DOACS)

-Among this class, apixaban would be preferred, although there is some potential for drug-drug interaction. Reduce dose per prescribing information [37] and monitor for bleeding events

-Do not use rivaroxaban due to higher risk of drug-drug interaction

Warfarin

-Check international normalized ratio (INR) before starting mifepristone

-Recommend prophylactically reducing the dose of warfarin by 50\% at start of mifepristone

-Check INR within 48-72 $\mathrm{h}$ after starting mifepristone and recheck again after an additional $72 \mathrm{~h}$

-Check INR following any change in mifepristone dose (within 48-72 h) and recheck again after an additional $72 \mathrm{~h}$

-After follow-up monitoring and no additional changes to warfarin, have patient continue to monitor INR per anticoagulant clinic guidance

\section{Antidiabetes medications}

Insulin

-Closely monitor patients for frequent dose adjustments during mifepristone initiation and titration

•Educate patients to self-monitor glucose levels several times daily, and if possible, arrange for online glucose data sharing

-Use extreme caution when treating patients with premixed insulins or concentrated insulins (e.g., U-500)

-Expect a decrease in patient caloric intake with mifepristone (reduction in hyperphagia)

-Consider proactive adjustment of insulin dose prior to starting mifepristone:

- If patient is on basal insulin only, consider reducing dose by 10-20\%

- If patient is on basal/bolus insulin, consider reducing bolus insulin by $50 \%$ in addition to $10-20 \%$ reduction in basal insulin, particularly in patients with severe insulin resistance

Non-insulin agents

-Consider stopping sulfonylureas and meglitinides or reducing dose by $50 \%$ prior to starting mifepristone because of hypoglycemia risk

-There is a potential drug-drug interaction between mifepristone and repaglinide

-Caution against initiating a GLP-1 agonist at same time as mifepristone due to gastrointestinal side effects

-SGLT-2 inhibitors carry a risk of fungal infection (genital mycotic infection). Monitor patients for volume depletion.

Abbreviations: ACE angiotensin-converting-enzyme, ARB angiotensin II receptor blocker, eGFR estimated glomerular filtration rate, GLP-1 glucagon-like peptide-1, INR international normalized ratio, MR mineralocorticoid receptor, NSAIDs nonsteroidal anti-inflammatory drugs, SGLT-2 sodium-glucose co-transporter-2

\section{Antidiabetes medications}

Mifepristone will increase the risk of hypoglycemia when used in combination with insulins, sulfonylureas, or meglitinides. Patients receiving these antidiabetes medications will need frequent monitoring, and the medications may need to be reduced or discontinued during mifepristone initiation and treatment. Clinicians should expect insulin resistance to improve with mifepristone treatment [5, 9]. Decreased appetite, increased satiety, or nausea during mifepristone treatment may also lower insulin requirements. Extreme caution is necessary when managing patients on premixed insulins 
Table 3 Commonly encountered drug-drug interactions with mifepristone

\begin{tabular}{|c|c|c|}
\hline Drug & Interaction $^{\mathrm{a}}$ & Impact $^{\mathrm{a}}$ \\
\hline \multicolumn{3}{|c|}{ HMG-CoA reductase inhibitors } \\
\hline Simvastatin & CYP3A4 metabolism & \multirow{4}{*}{$\begin{array}{l}\text { Increased serum concentration of statins, } \\
\text { resulting in increased side effects }\end{array}$} \\
\hline Lovastatin & CYP3A4 metabolism & \\
\hline Atorvastatin & $\begin{array}{l}\text { CYP3A4 metabolism } \\
\text { (lesser extent) }\end{array}$ & \\
\hline Fluvastatin & $\begin{array}{l}\text { CYP3A4 metabolism } \\
\text { (lesser extent) }\end{array}$ & \\
\hline \multicolumn{3}{|l|}{ Opioids } \\
\hline $\begin{array}{l}\text { Hydrocodone/ } \\
\text { APAP }\end{array}$ & CYP3A4 metabolism & $\begin{array}{l}\text { Increased serum concentrations of opioids, } \\
\text { increasing side effects }\end{array}$ \\
\hline \multicolumn{3}{|l|}{ Oxycodone } \\
\hline \multicolumn{3}{|l|}{ Tramadol } \\
\hline Methadone & $\begin{array}{l}\text { CYP3A4 metabolism } \\
\text { and QT } \\
\text { prolongation risk }\end{array}$ & $\begin{array}{l}\text { Increased serum concentrations of } \\
\text { methadone, increasing side effects, and risk } \\
\text { of life-threatening QT prolongation }\end{array}$ \\
\hline Fentanyl & CYP3A4 metabolism & $\begin{array}{l}\text { Increased serum concentrations of fentanyl, } \\
\text { leading to serious, life-threatening respiratory } \\
\text { depression }\end{array}$ \\
\hline
\end{tabular}

Recommended approach ${ }^{a}$

Contraindicated - switch to rosuvastatin or pravastatin

Contraindicated - switch to rosuvastatin or pravastatin

Switch to rosuvastatin or pravastatin OR lower dose (no more than $20 \mathrm{mg}$ )

Switch to rosuvastatin or pravastatin OR lower dose (no more than $20 \mathrm{mg}$ )

Use lowest effective dose and monitor for side effects

Use lowest effective dose and monitor for side effects and EKG changes regularly. Switch to alternative opioid if possible.

Contraindicated - switch to alternative opioid

Increase frequency of INR monitoring. Use lowest effective dose (consider 50\% reduction). Monitor after starting mifepristone and with dose titrations.

Not recommended

Reduce dose of apixaban per prescribing information [37]; monitor for bleeding events

Hold mifepristone temporarily while treating infection

\section{Azithromycin \\ Ciprofloxacin \\ Levofloxacin \\ Moxifloxacin \\ Sulfamethoxazole/ \\ Trimethoprim}

QT prolongation ${ }^{b}$

Risk of QT prolongation

\section{Benzodiazepines}

Alprazolam

CYP3A4 metabolism

ncreased serum concentrations of

Clonazepam

Diazepam

Triazolam

Flurazepam

\section{Second generation (atypical) antipsychotics}

Quetiapine

Risperidone

Aripiprazole

Lurasidone

\section{Anticonvulsants}

Phenobarbital

Phenytoin

CYP3A4 metabolism (major) and QT prolongation $^{\mathrm{a}}$

CYP3A4 metabolism (major)

Induce CYP3A4 metabolism (strong)
Increased serum concentrations of antipsychotic, increasing side effects and risk of QT prolongation

Increased serum concentrations, increasing side effects of lurasidone

Decreased serum concentrations of mifepristone
Depending on indication, preferred agents would be lorazepam or oxazepam for anxiety and temazepam for sleep

Reduce dose and monitor patient and EKG

Contraindicated with strong CYP3A inhibitors per prescribing information

Monitor for clinical endpoints and patient's improvement. Monitor for changes in seizure activity.

Carbamazepine 
Table 3 Commonly encountered drug-drug interactions with mifepristone (Continued)

\begin{tabular}{|c|c|c|c|}
\hline Drug & Interaction $^{\mathrm{a}}$ & Impact $^{\mathrm{a}}$ & Recommended approach $^{\mathrm{a}}$ \\
\hline Oxcarbazepine & $\begin{array}{l}\text { Induces CYP3A4 } \\
\text { (weak) }\end{array}$ & & \\
\hline \multicolumn{4}{|l|}{ Miscellaneous } \\
\hline Diltiazem & \multirow[t]{2}{*}{ CYP3A4 metabolism } & \multirow{2}{*}{$\begin{array}{l}\text { Increased serum concentrations of } \\
\text { mifepristone, diltiazem, and verapamil }\end{array}$} & \multirow{2}{*}{$\begin{array}{l}\text { Limit doses of both drugs. Start mifepristone at low } \\
\text { doses and perform small and careful dose escalations. }\end{array}$} \\
\hline Verapamil & & & \\
\hline Repaglinide & CYP2C8/2C9 & $\begin{array}{l}\text { Increased serum concentrations of } \\
\text { repaglinide, increasing side effects }\end{array}$ & $\begin{array}{l}\text { Reduce dose or use smallest recommended dose. } \\
\text { Monitor blood glucose levels more frequently, especially } \\
\text { postprandial levels. }\end{array}$ \\
\hline $\begin{array}{l}\text { Non-steroidal } \\
\text { anti-inflammatory } \\
\text { drugs (NSAIDs) }\end{array}$ & CYP2C8/2C9 & $\begin{array}{l}\text { Increased serum concentrations of NSAIDs, } \\
\text { increasing side effects }\end{array}$ & $\begin{array}{l}\text { Avoid if possible or use smallest recommended dose } \\
\text { and monitor for side effects }\end{array}$ \\
\hline
\end{tabular}

or concentrated insulins, such as U-500. See Table 2 for specific proactive insulin dose-adjustment strategies.

When counseling patients, it is essential to emphasize the importance of self-monitoring blood glucose and instruct patients how to down-titrate insulin to avoid hypoglycemia (i.e., reducing or eliminating bolus insulin if limiting caloric intake or skipping meals). The use of continuous blood glucose monitoring devices should also be considered as a method of monitoring glycemic excursions while on mifepristone.

Consider reducing the doses of sulfonylureas and meglitinides by $50 \%$ or stopping these medications when mifepristone is started. Other noninsulin antihyperglycemic agents may typically be used with mifepristone with some specific cautions (see Table 2).

\section{Drug-drug interactions}

Mifepristone is metabolized primarily via CYP3A4 and is an inhibitor of CYP3A4 [16, 39, 40]. Mifepristone also inhibits CYP2C8/9 [16]. Therefore, communication with patients and other providers is essential to help prevent potential drug-drug interactions. When using a concomitant strong CYP3A inhibitor (e.g., ketoconazole, itraconazole, ritonavir, clarithromycin), the dose of mifepristone should be limited to $900 \mathrm{mg} /$ day [16]. Additional drugdrug interactions with mifepristone are listed in Table 3. Instruct patients to consult with the clinician and pharmacist managing their mifepristone before starting or stopping any other drug, including over-the-counter drugs and supplements. Clinicians and pharmacists should perform periodic medication reconciliations, particularly following a hospitalization or ER visit.

\section{Special clinical situations}

\section{Surgery}

There is a lack of prospective data to support detailed recommendations for the management of mifepristone in the surgical setting. In general, surgical considerations should include mifepristone's long half-life ( $\sim 55 \mathrm{~h})$ [16]. Based on the half-life it of mifepristone, it would take approximately 2 weeks to clear from circulation [12]. In the SEISMIC study, serum cortisol levels declined to pre-mifepristone levels at the protocol-specified 6-week post-treatment assessment [5] visit. Additional surgical considerations include the impact of mifepristone on perioperative biochemical measurements, as mifepristone may increase serum cortisol and ACTH levels, and the potential risk of developing symptoms of excess GR antagonism. One must also consider the effects of discontinuing mifepristone and the potential reemerging effects of hypercortisolism on surgical outcomes (worsening glycemic control, hypercoagulability, hemodynamic and electrolyte status and blood pressure changes, potassium level alterations, and impaired postsurgical wound healing). Patients should monitor their blood pressure readings when discontinuing mifepristone.

\section{Non-hypercortisolemic-related surgery and emergency surgery}

If mifepristone is held prior to non-hypercortisolemicrelated surgery, the MR antagonist may also need to be held. The half-lives of spironolactone and its active metabolites range from 1.4 to $16.5 \mathrm{~h}$ [41]. Because of the shorter half-life of spironolactone compared with mifepristone (up to $85 \mathrm{~h}$ ), spironolactone should be continued until 2-3 days before surgery. If necessary, for patients in an emergency surgical situation, discontinue mifepristone and administer dexamethasone. We recommend a conservative approach to dexamethasone dosing, using $2 \mathrm{mg}$ daily (intravenously or by mouth) for every $300 \mathrm{mg}$ of mifepristone previously administered [11]. Monitor for signs and symptoms of excess GR antagonism (see Fig. 1), as previously discussed. Mifepristone may be restarted 1 week postoperatively, once the patient has 
normal oral intake, no significant gastrointestinal complaints, and is no longer at risk for postoperative bleeding. Restart mifepristone at the presurgical maintenance dose if tolerated.

\section{Bridge therapy}

Mifepristone has been used as a temporary "bridge" therapy in patients receiving pituitary radiotherapy [42] and as pre-treatment in high-risk patients to reduce perioperative risk and improve postoperative outcomes, such as eliminating or reducing the length of postoperative adrenal insufficiency in some patients [43-47].

Monitoring serum cortisol and ACTH levels over time may be helpful in patients treated with pituitary radiotherapy who are also receiving mifepristone bridge therapy in order to detect the onset of radiotherapy treatment effect, as levels would begin to decrease. Patients must also be monitored for signs and symptoms of AI.

Perioperative management protocols for ACTHdependent disease vary widely amongst centers and usually include measurements of postoperative $\mathrm{ACTH}$ and cortisol levels as indicators of treatment success and risk of relapse. These protocols may need to be modified when managing patients pretreated with mifepristone since mifepristone indirectly increases ACTH secretion from healthy pituitary corticotroph cells. Mifepristone may also be used to control disease following failed surgical procedures while other treatment options are considered.

Patients with unilateral primary adrenal hypercortisolism can also be treated with mifepristone prior to adrenalectomy. Mifepristone affects the hypothalamicpituitary-adrenal (HPA) axis by antagonizing cortisol activity, which reduces negative feedback at the hypothalamus and corticotrophs, leading to increased ACTH secretion $[5,44,48]$. In patients with unilateral primary adrenal hypercortisolism, the rise in ACTH indicates recovery of previously suppressed corticotrophs [44]. Up to 6 months of pre-treatment with mifepristone may be required to achieve this effect. The increase in $\mathrm{ACTH}$ in turn decreases the suppression of cortisol secretion from the contralateral adrenal gland before unilateral adrenalectomy, thereby preventing adrenal atrophy and postoperative AI. This has been shown in a clinical case report [44], where increases in $\mathrm{ACTH}$, accompanied by increases in cortisol and dehydroepiandrosterone sulfate, were monitored as markers of HPA axis reactivation during mifepristone pre-treatment. Additional studies are needed to examine the benefit of GR antagonists as pre-treatment in patients with unilateral adrenal hypercortisolism.

\section{Infection/sick days}

We recommend assessing the patient for signs and symptoms of excess GR antagonism. If no acute signs or symptoms are present, the patient does not likely require supplemental dexamethasone. Clinical judgement is required. Maintain communication with the patient and exercise caution when prescribing antibiotics to prevent any potential drug-drug interactions (see Table 3 ).

\section{Exogenous glucocorticoid use}

Mifepristone treatment is not appropriate for patients requiring high-dose exogenous glucocorticoid therapies for other underlying conditions. Mifepristone will inhibit the efficacy of these glucocorticoid therapies. Consider switching patients with asthma or chronic obstructive pulmonary disease from glucocorticoid inhalers to long-acting beta-adrenergic or long-acting anticholinergic inhalers. Patients with chronic musculoskeletal pain may experience increased pain when treated with mifepristone due to GR antagonism and may require intensified pain management. If pain medication is needed, check for drug-drug interactions. Consultation with a pain specialist or rheumatologist may be helpful. If a patient on mifepristone subsequently requires exogenous glucocorticoids for comorbidities, for example following a hospital admission, we suggest reevaluating the appropriateness of mifepristone therapy.

\section{Special populations}

In the SEISMIC study, adult patients up to 71 years of age were treated with mifepristone [5]. We recommend the following considerations for the use of mifepristone in older patients ( $>65$ years):

- Older patients may be prone to develop mild hypovolemia; monitor volume status and GFR, particularly when adding an MR antagonist

- Older patients often receive polypharmacy; monitor for potential drug-drug interactions

- Slower titration may help improve tolerability

Reports of mifepristone use in pediatric patients with CS are limited [31, 49, 50]. In one report, a 16-year-old girl with Cushing disease was treated with mifepristone for 8 years after multiple interventions failed, including transsphenoidal surgery and pituitary radiation [31]. During treatment, she developed endometrial hypertrophy and was given a 2-month mifepristone holiday every 4-6 months, together with a course of medroxyprogesterone to induce decidual bleeding.

Some patients with nonalcoholic fatty liver disease (NAFLD) have shown subtle, chronic dysregulation of the HPA axis that correlates with the severity of liver histopathology, suggesting that hypercortisolism may be implicated in the development of NAFLD [51]. Limited data have shown improvement in liver enzymes in patients with NAFLD treated with mifepristone [52]. 
Further studies are needed regarding the effectiveness of mifepristone in patients with co-existing fatty liver disease.

\section{Other clinical considerations}

Insulin-like growth factor 1 (IGF-1) levels are elevated in some patients with endogenous hypercortisolism and decrease with GR antagonism [53, 54]. Mifepristone treatment is also associated with reversible decreases in high-density lipoprotein (HDL) cholesterol and HDL particle concentrations along with increases in the efflux capacity of serum HDL (per particle) [5, 55]. The effects of mifepristone treatment on HDL function, thrombo-embolic complications, and cardiovascular outcomes in the setting of CS have not been established $[5,55]$.

\section{Conclusion}

Mifepristone is a useful medical treatment option for patients with endogenous hypercortisolism, and requires specific clinical considerations and monitoring to ensure optimal patient care and treatment benefit. These consensus recommendations provide practical guidance for the appropriate use of mifepristone and should be used alongside current guidelines for the treatment of endogenous hypercortisolism. Of note, some of the mifepristone clinical management topics discussed do not appear to be dose-dependent, such as those pertaining to thyroid function, endometrial thickening, and vaginal bleeding; therefore, mifepristone dose reductions were not recommended management strategies in those cases.

Close communication with patients during mifepristone treatment is critically important. Evaluation of the efficacy and safety of mifepristone relies heavily on clinical signs and feedback from patients about their symptoms. Therefore, shared decision-making is essential when formulating a mifepristone treatment plan and evaluating its efficacy. Additional assessments may be needed to further differentiate between symptoms of cortisol withdrawal and excess GR antagonism. Communication with other healthcare providers involved in the patient's care is also critically important, particularly with regards to concomitant medication management.

\footnotetext{
Abbreviations

11ßHSD2: Hydroxysteroid dehydrogenase type 2; 5-HT3: 5-hyroxytryptamine 3; AACE: American Association of Clinical Endocrinologists; ACE: Angiotensin converting enzyme; ACTH: Adrenocorticotropic hormone; Al: Adrenal insufficiency; APAP: Acetaminophen; ARB: Angiotensin II receptor blocker; ATA: American Thyroid Association; BMJ: British Medical Journal; CS: Cushing syndrome; CYP: Cytochrome P450; DASH: Dietary Approaches to Stop Hypertension; eGFR: Estimated glomerular filtration rate; DOAC: Direct oral anticoagulant; EKG: Electrocardiogram; FDA: US Food and Drug Administration; GLP-1: Glucagon-like peptide-1; GR: Glucocorticoid receptor; HDL: High-density lipoprotein; HPA: Hypothalamic-pituitary-adrenal; IGF1: Insulin-like growth factor 1; INR: International normalized ratio; MAGI
}

C: MAGIC (Making Grade the Irresistible Choice) Foundation; MR: Mineralocorticoid receptor; NAFLD: Nonalcoholic fatty liver disease; NSAI Ds: Nonsteroidal anti-inflammatory drugs; PCP: Primary care physician; PR: Progesterone receptor; SEISMIC: Study of the Efficacy and Safety of Mifepristone in the Treatment of Endogenous Cushing Syndrome trial; SGLT2: Sodium-glucose co-transporter-2; T3: Tri-iodothyronine; T4: Serum thyroxine; TENS: Transcutaneous electrical nerve stimulation; TSH: Thyroidstimulating hormone

\section{Acknowledgements}

The authors thank Sarah Mizne, PharmD, and Don Fallon, ELS, of MedVal Scientific Information Services, LLC (Princeton, NJ) for medical writing and editorial assistance, which were funded by Corcept Therapeutics. The authors also thank Behn Sarafpour, PharmD; Michele Lamerson, RN, MS, CPNP; Rebecca Ray, APRN, FNP-C; and Dat Nguyen, PharmD, of Corcept Therapeutics for valuable scientific support in preparation of the consensus meeting and discussions.

\section{Authors' contributions}

All authors made substantial contributions to the conception and design of this work, and all have been involved in drafting or substantively revising the manuscript. All authors meet ICMJE criteria for authorship, take responsibility for the integrity of the work as a whole, and have given their approval for this version to be submitted. The authors read and approved the final manuscript.

\section{Funding}

Corcept Therapeutics (Menlo Park, California, USA) funded the Consensus Advisory Board; discussion during this event contributed to these consensus recommendations. Corcept Therapeutics also funded the preparation of this manuscript for publication, including medical writing and editorial assistance, and the Open Access Fee. This manuscript was prepared according to the International Society for Medical Publication Professionals' "Good Publication Practice for Communicating Company-Sponsored Medical Research: GPP3."

\section{Availability of data and materials}

Data sharing is not applicable to this article as no datasets were generated or analyzed during the current study.

\section{Ethics approval and consent to participate}

Not applicable.

\section{Consent for publication}

Not applicable.

\section{Competing interests}

D.R.B has been a consultant/advisor for Corcept and a speaker for Corcept, Merck, and Novo Nordisk.

H.E.E. has been a consultant/advisor for Amgen and Corcept, a speaker for Amgen, BI/Lilly, and Corcept, and has received research support from Acasti and Corcept.

B.S.E. has been a consultant/advisor for Corcept.

M.B.G. has been a consultant/advisor for Corcept and Novo Nordisk, and has received research support from Camurus, Corcept, Crinetics, Ionis, Ipsen,

Novartis, Novo Nordisk, Opko, Teva, and Strongbridge.

E.E.K. has been a consultant/advisor and speaker for Corcept.

L.A.K. has been a consultant/advisor for Corcept and a speaker for Corcept, Ipsen, and Strongbridge.

B.S. reports that Optime Care, Inc. is the limited distribution contracted pharmacy for Corcept Therapeutics to dispense mifepristone.

S.L.S. has received research support from Corcept and Novartis.

K.C.J.Y. has been a consultant/advisor for Corcept, Novartis, and Strongbridge, and has received research support from Corcept, Crinetics, Millendo, and Novartis.

H.Y. has been a consultant/advisor and a speaker for Corcept. All authors, except Dr. Salke, received a consulting fee from Corcept for participating in the Consensus Advisory Board in May 2019. Discussion during this event contributed to these consensus recommendations. 


\section{Author details}

${ }^{1}$ Private Practice, Endocrinology, Diabetes, and Metabolism, Rockville, MD, USA. ${ }^{2}$ Metabolic Medicine of Mississippi, Jackson, MS, USA. ${ }^{3}$ Regional Diabetes Center, St. Elizabeth Physicians, Covington, KY, USA. ${ }^{4}$ Allegheny Neuroendocrinology Center, Allegheny General Hospital, Pittsburgh, PA, USA. ${ }^{5}$ Endocrine Associates of Dallas, Dallas, TX, USA. ${ }^{6}$ Midtown Endocrine Associates, Phoenix, AZ, USA. ${ }^{7}$ Optime Care, Earth City, MO, USA. ${ }^{8}$ Pituitary Center, Baylor St. Luke's Medical Center, Baylor College of Medicine, Houston, TX, USA. ${ }^{9}$ Barrow Neurological Institute and St. Joseph's Hospital and Medical Center, University of Arizona College of Medicine and Creighton School of Medicine, Phoenix, AZ, USA. ${ }^{10}$ Division of Endocrinology, Diabetes, and Metabolism, The University of Central Florida College of Medicine, 13800 Veterans Way, Orlando, FL 32827, USA.

\section{Received: 10 June 2020 Accepted: 1 September 2020} Published online: 29 October 2020

\section{References}

1. Nieman LK, Biller BM, Findling JW, Murad MH, Newell-Price J, Savage MO, Tabarin A. Endocrine Society. Treatment of Cushing's syndrome: an Endocrine Society clinical practice guideline. J Clin Endocrinol Metab. 2015; 100(8):2807-31.

2. Carroll TB, Javorsky BR, Findling JW. Postsurgical recurrent Cushing disease: clinical benefit of early intervention in patients with normal urinary free cortisol. Endocr Pract. 2016;22(10):1216-23.

3. Minniti G, Osti M, Jaffrain-Rea ML, Esposito V, Cantore G, Maurizi ER. Longterm follow-up results of postoperative radiation therapy for Cushing's disease. J Neuro-Oncol. 2007;84(1):79-84.

4. Hamrahian AH, Yuen KCJ, Hoffman AR. AACE neuroendocrine and pituitary scientific committee. AACE/ACE disease state clinical review: medical management of Cushing disease. Endocr Pract. 2014;20(7):746-57.

5. Fleseriu M, Biller BM, Findling JW, Molitch ME, Schteingart DE, Gross C. Mifepristone, a glucocorticoid receptor antagonist, produces clinical and metabolic benefits in patients with Cushing's syndrome. J Clin Endocrinol Metab. 2012;97(6):2039-49.

6. Fleseriu M, Findling JW, Koch CA, Schlaffer S-M, Buchfelder M, Gross C. Changes in plasma ACTH levels and corticotroph tumor size in patients with Cushing's disease during long-term treatment with the glucocorticoid receptor antagonist mifepristone. J Clin Endocrinol Metab. 2014;99(10): 3718-27.

7. Katznelson L, Loriaux DL, Feldman D, Braunstein GD, Schteingart DE, Gross C. Global clinical response in Cushing's syndrome patients treated with mifepristone. Clin Endocrinol. 2014;80(4):562-9.

8. Yuen KC, Williams G, Kushner H, Nguyen D. Association between mifepristone dose, efficacy, and tolerability in patients with Cushing syndrome. Endocr Pract. 2015;21(10):1087-92.

9. Wallia A, Colleran K, Purnell JQ, Gross C, Molitch ME. Improvement in insulin sensitivity during mifepristone treatment of Cushing syndrome: early and late effects. Diabetes Care. 2013;36(9):e147-e8.

10. Fein HG, Vaughan TB 3rd, Kushner H, Cram D, Nguyen D. Sustained weight loss in patients treated with mifepristone for Cushing's syndrome: a followup analysis of the SEISMIC study and long-term extension. BMC Endocr Disord. 2015;15:63.

11. Carroll T, Findling JW. The use of mifepristone in the treatment of Cushing's syndrome. Drugs Today (Barc). 2012;48(8):509-18.

12. Fleseriu M, Molitch ME, Gross C, Schteingart DE, Vaughan TB 3rd, Biller BM. A new therapeutic approach in the medical treatment of Cushing's syndrome: glucocorticoid receptor blockade with mifepristone. Endocr Pract. 2013;19(2):313-26.

13. Bhattacharyya A, Kaushal K, Tymms DJ, Davis JR. Steroid withdrawal syndrome after successful treatment of Cushing's syndrome: a reminder. Eur J Endocrinol. 2005;153(2):207-10.

14. Raff H, Sharma ST, Nieman LK. Physiological basis for the etiology, diagnosis, and treatment of adrenal disorders: Cushing's syndrome, adrenal insufficiency, and congenital adrenal hyperplasia. Compr Physiol. 2014;4(2): 739-69.

15. Schrier RW. Body water homeostasis: clinical disorders of urinary dilution and concentration. J Am Soc Nephrol. 2006;17(7):1820-32.

16. Korlym ${ }^{\circledast}$ (mifepristone) 300 mg tablets [prescribing information]. Menlo Park, CA: Corcept Therapeutics Incorporated; 2019. https://www.korlym.com/wp-
content/uploads/2018/01/K-00017-NOV-2019_electronic-PI_r8_FINAL.pdf. Accessed 24 June 2020.

17. Rushworth RL, Torpy DJ, Falhammar H. Adrenal crisis. N Engl J Med. 2019; 381(9):852-61.

18. Takasu N, Komiya I, Nagasawa Y, Asawa T, Yamada T. Exacerbation of autoimmune thyroid dysfunction after unilateral adrenalectomy in patients with Cushing's syndrome due to an adrenocortical adenoma. N Engl J Med. 1990;322(24):1708-12.

19. Noguchi Y, Tamai H, Fujisawa K, Nagano J, Mukuta T, Komaki G, Masubayashi S, Kubo C, Torisu M, Nakagaki H, Imayama S. Systemic lupus erythematosus after pituitary adenomectomy in a patient with Cushing's disease. Clin Endocrinol. 1998;48(5):670-2.

20. Senecal JL, Uthman I, Beauregard H. Cushing's disease-induced remission of severe rheumatoid arthritis. Arthritis Rheum. 1994;37(12):1826.

21. Torpy DJ, Mullen N, Ilias I, Nieman LK. Association of hypertension and hypokalemia with Cushing's syndrome caused by ectopic ACTH secretion: a series of 58 cases. Ann N Y Acad Sci. 2002;970:134-44.

22. Howlett TA, Drury PL, Perry L, Doniach I, Rees LH, Besser GM. Diagnosis and management of ACTH-dependent Cushing's syndrome: comparison of the features in ectopic and pituitary ACTH production. Clin Endocrinol. 1986; 24(6):699-713.

23. Ulick S, Wang JZ, Blumenfeld JD, Pickering TG. Cortisol inactivation overload: a mechanism of mineralocorticoid hypertension in the ectopic adrenocorticotropin syndrome. J Clin Endocrinol Metab. 1992;74(5):963-7.

24. US Department of Health and Human Services, US Department of Agriculture. Dietary Guidelines for Americans, 2015-2020. 8th edition. 2015. https://health.gov/dietaryguidelines/2015/resources/2015-2020_Dietary_ Guidelines.pdf. Accessed July 29, 2019.

25. Berger C, Boggavarapu N, Norlin E, Queckborner S, Hornaeus K, Falk A, Engman M, Ramstrom M, Lalitkumar PGL, Gemzell-Danielsson K. Molecular characterization of PRM-associated endometrial changes, PAEC, following mifepristone treatment. Contraception. 2018;98(4):317-22.

26. Mutter GL, Bergeron C, Deligdisch L, Ferenczy A, Glant M, Merino M, Williams AR, Blithe DL. The spectrum of endometrial pathology induced by progesterone receptor modulators. Mod Pathol. 2008;21(5):591-8.

27. Carroll TB, loffe O, Spitz IM, Gross C, Cram D, Hamrahian AH. Endometrial effects of long-term mifepristone (MIFE) treatment of Cushing's syndrome: results from the SEISMIC studies. Endocr Rev. 2013;34(suppl 1):SUN-52.

28. Fiscella J, Bonfiglio T, Winters P, Eisinger SH, Fiscella K. Distinguishing features of endometrial pathology after exposure to the progesterone receptor modulator mifepristone. Hum Pathol. 2011;42(7):947-53.

29. Eisinger SH, Meldrum S, Fiscella K, le Roux HD, Guzick DS. Low-dose mifepristone for uterine leiomyomata. Obstet Gynecol. 2003;101(2):243-50.

30. Eisinger SH, Bonfiglio T, Fiscella K, Meldrum S, Guzick DS. Twelve-month safety and efficacy of low-dose mifepristone for uterine myomas. J Minim Invasive Gynecol. 2005;12(3):227-33.

31. Basina M, Liu H, Hoffman AR, Feldman D. Successful long-term treatment of Cushing disease with mifepristone (RU486). Endocr Pract. 2012;18(5):e114e20.

32. Guarda FJ, Findling J, Yuen KCJ, Fleseriu M, Nachtigall LB. Mifepristone increases thyroid hormone requirements in patients with central hypothyroidism: a multicenter study. J Endocr Soc. 2019;3(9):1707-14.

33. Heikinheimo O, Ranta S, Grunberg S, Lahteenmaki P, Spitz IM. Alterations in the pituitary-thyroid and pituitary-adrenal axes--consequences of long-term mifepristone treatment. Metabolism. 1997:46(3):292-6.

34. Garber JR, Cobin RH, Gharib H, Hennessey JV, Klein I, Mechanick JI, PessahPollack R, Singer PA, Woeber KA. American Association of Clinical Endocrinologists and American Thyroid Association Taskforce on hypothyroidism in adults. Clinical practice guidelines for hypothyroidism in adults: cosponsored by the American Association of Clinical Endocrinologists and the American Thyroid Association. Endocr Pract. 2012; 18(6):988-1028

35. Bekkering GE, Agoritsas T, Lytvyn L, Heen AF, Feller M, Moutzouri E, Abdulazeem H, Aertgeerts B, Beecher D, Brito JP, Farhoumand PD, Singh Ospina N, Rodondi N, van Driel M, Wallace E, Snel M, Okwen PM, Siemieniuk $\mathrm{R}$, Vandvik PO, Kuijpers T, Vermandere M. Thyroid hormones treatment for subclinical hypothyroidism: a clinical practice guideline. BMJ. 2019;365:12006.

36. US Center for Drug Evaluation and Research. Clinical review: mifepristone tablets. NDA application number: 202107Orig1s000. 2012. https://www. accessdata.fda.gov/drugsatfda_docs/nda/2012/2021070rig1s000MedR.pdf. Accessed June 24, 2019 
37. Eliquis ${ }^{\circledast}$ (apixaban) tablets, for oral use [prescribing information]. Princeton, NJ: Bristol-Myers Squibb Company; 2019. https://packageinserts.bms.com/pi/ pi_eliquis.pdf. Accessed 24 June 2020.

38. Xarelto (rivaroxaban) tablets, for oral use [prescribing information]. Titusville, NJ: Janssen Pharmaceuticals, Inc.; 2020. http://www.janssenlabels. com/package-insert/product-monograph/prescribing-information/XARELTOpi.pdf. Accessed 24 June 2020.

39. Jang GR, Wrighton SA, Benet LZ. Identification of CYP3A4 as the principal enzyme catalyzing mifepristone (RU 486) oxidation in human liver microsomes. Biochem Pharmacol. 1996;52(5):753-61.

40. He K, Woolf TF, Hollenberg PF. Mechanism-based inactivation of cytochrome P-450-3A4 by mifepristone (RU486). J Pharmacol Exp Ther. 1999;288(2):791-7.

41. Gardiner P, Schrode K, Quinlan D, Martin BK, Boreham DR, Rogers MS, Stubbs K, Smith M, Karim A. Spironolactone metabolism: steady-state serum levels of the sulfur-containing metabolites. J Clin Pharmacol. 1989;29(4):3427.

42. Castinetti F, Fassnacht M, Johanssen S, Terzolo M, Bouchard P, Chanson P, Do Cao C, Morange I, Pico A, Ouzounian S, Young J, Hahner S, Brue T, Allolio B, Conte-Devolx B. Merits and pitfalls of mifepristone in Cushing's syndrome. Eur J Endocrinol. 2009;160(6):1003-10.

43. Sack PA, Smith JJ. Mifepristone therapy prior to pituitary surgery in Cushing disease prevented need for long-term glucocorticoid replacement. Endocr Pract. 2018:39(2 suppl): SAT-578.

44. Saroka RM, Kane MP, Robinson L, Busch RS. No postoperative adrenal insufficiency in a patient with unilateral cortisol-secreting adenomas treated with mifepristone before surgery. Clin Med Insights Endocrinol Diab. 2016;9: 31-6.

45. Magaji V, Park SY, Mastoris K, Bucciarelli M, Beman S. Mifepristone utilization in Cushing's from large bilateral adrenal adenoma prior to surgery. J Endocrinol Metab. 2015;5(3):226-8.

46. Moraitis AG, Auchus RJ. Clinical and hormonal response to mifepristone therapy in 2 patients with ACTH-independent Cushing syndrome. ACCE Clin Case Rep. 2015;1(3):e204-e7.

47. Cohan P, East HE, Galati SJ, Mercado JU, Lim PJ, Lamerson M, Smith JJ, Peters AL, Yuen KCJ. Mifepristone treatment in four cases of primary bilateral macronodular adrenal hyperplasia (BMAH). J Clin Endocrinol Metab. 2019;104(12):6279-90.

48. Debono M, Chadarevian R, Eastell R, Ross RJ, Newell-Price J. Mifepristone reduces insulin resistance in patient volunteers with adrenal incidentalomas that secrete low levels of cortisol: a pilot study. PLoS One. 2013;8(4):e60984.

49. Banerjee RR, Marina N, Katznelson L, Feldman BJ. Mifepristone treatment of Cushing's syndrome in a pediatric patient. Pediatrics. 2015;136(5):e1377-e81.

50. Newfield RS, Spitz IM, Isacson C, New MI. Long-term mifepristone (RU486) therapy resulting in massive benign endometrial hyperplasia. Clin Endocrinol. 2001;54(3):399-404.

51. Targher G, Bertolini L, Rodella S, Zoppini G, Zenari L, Falezza G. Associations between liver histology and cortisol secretion in subjects with nonalcoholic fatty liver disease. Clin Endocrinol. 2006;64(3):337-41.

52. Ragucci $E$, Nguyen D, Lamerson M, Moraitis AG. Effects of mifepristone on nonalcoholic fatty liver disease in a patient with a cortisol-secreting adrenal adenoma. Case Rep Endocrinol 2017;2017:6161348.

53. Moraitis A, Feelders R, Gordon M, lacuaniello D, Kargi A, Pivonello R. IGF-1 levels in patients with hypercortisolism and effects of medical therapy with relacorilant, a selective cortisol modulator. Endocr Pract. 2018;24(suppl 1): 318-9.

54. Gordon MB, Spiller KL, Bunta R, Gordon MS. Persistent acromegaly controlled on pegvisomant with co-existing non-ACTH dependent Cushing's syndrome (CS) due to bilateral adrenal adenomas with dramatic clinical response to mifepristone. Endocr Rev. 2016;37(2 suppl 1):SUN 555.

55. Page ST, Krauss RM, Gross C, Ishida B, Heinecke JW, Tang C, Amory JK, Schaefer PM, Cox CJ, Kane J, Purnell JQ, Weinstein RL, Vaisar T. Impact of mifepristone, a glucocorticoid/progesterone antagonist, on HDL cholesterol, HDL particle concentration, and HDL function. J Clin Endocrinol Metab. 2012;97(5):1598-605

\section{Publisher's Note}

Springer Nature remains neutral with regard to jurisdictional claims in published maps and institutional affiliations.

Ready to submit your research? Choose BMC and benefit from:

- fast, convenient online submission

- thorough peer review by experienced researchers in your field

- rapid publication on acceptance

- support for research data, including large and complex data types

- gold Open Access which fosters wider collaboration and increased citations

- maximum visibility for your research: over $100 \mathrm{M}$ website views per year

At BMC, research is always in progress.

Learn more biomedcentral.com/submissions 